\title{
PARALISIA FACIAL PERIFÉRICA E OTITE MÉDIA TUBERCULOSA
}

\author{
José Geraldo Camargo lima * \\ Nelson Alvares Cruz **
}

A paralisia facial periférica é produzida por causas diversas, sendo a maioria dos casos constituída pela paralisia de Bell. Por ter observado paralisia facial em otite tuberculosa julgamos oportuno relato do caso por duas razōes: 1) a dificuldade para se fazer o diagnóstico etiológico correto por ocasião dos primeiros exames; 2) a raridade da etiologia tuberculosa como causa de paralisia facial.

A freqüência das otites tuberculosas baixou muito após a introdução dos medicamentos antituberculosos modernos. Estatísticas antigas, que precedem a era dessas drogas, mostram que cerca de 3 a $5 \%$ das otites médias supuradas eram de origem tuberculosa (Theissing ${ }^{19}$ ). Duas estatisticas mais recentes, do periodo de vigência das novas drogas indicam a pequena incidência atual na afecção: no Royal National Throat, Nose and Ear Hospital de Londres, a otite média tuberculosa foi observada em 11 de 23.000 pacientes com otite média supurada $(0,05 \%)$, examinados entre os anos de 1950 e 1959 (Jeanes e Friedmann, citados por Midholm e Brahe-Pedersen ${ }^{11}$ ); em sanatórios para tuberculosos de Saint Hilaire du Touvet, na França, a otite média tuberculosa foi observada em 11 de 5.000 pacientes $(0,2 \%)$, examinados entre 1949 e 1959 (Piaget ${ }^{13}$ ). Quanto à idade de incidência da otite tuberculosa dados colhidos nos trabalhos que consultamos $2,3,5,6,8,10,11,14$, $15,16,17,18,20,21,22$, demonstram a seguinte distribuição: até 1 ano (13 casos), 1 a 2 anos ( 2 casos), 2 a 5 anos (4 casos), 5 a 10 anos (1 caso), 10 a 15 anos ( 0 casos) e acima de 15 anos (10 casos). Essa distribuição demonstra a tendência da otite tuberculosa instalar-se na criança, particularmente no lactente; contudo, em qualquer idade da vida é possível encontrá-la. Quanto à ocorrência da paralisia facial nas otites médias tuberculosas, na análise de 30 casos de literatura $5,6,15,17,18,20,21,22,9$ tiveram paralisia facial, o que representa $30 \%$. Para comparação com o que ocorre nas otites médias supuradas banais, Knoth e Fritsche ${ }^{7}$, baseados em 1866 casos, observaram paralisia facial em 1,9\% de otites médias agudas e em 1,7\% de otites médias crônicas inespecíficas. Aubry ${ }^{1}$ refere que essa complicação aparece com frequência de $1 \%$ nas otites médias agudas inespecíficas e de $3 \%$ nas crônicas

Trabalho do Departamento de Neurologia e Neurocirurgia e Disciplina de Otorrinolaringologia da Escola Paulista de Medicina, apresentado no $\mathrm{V}$ Congresso Brasileiro de Neurologia (São Paulo, 12-15 julho, 1972): * Professor Adjunto de Neurologia; * Professor Adjunto de Otorrinolaringologia. 
inespecificas. $\mathbf{E}$, assim, flagrante a diferença entre a extraordinária ocorrência de paralisia facial nas otites tuberculosas em relação ao que ocorre nas otites médias banais.

\section{OBSERVAÇÃO}

H. I., sexo feminino, branca, com 38 anos de idade, examinada em 30-7-1971 no nosso consultório por apresentar paralisia facial periférica direita há 8 dias e discretas dores de ouvido do mesmo lado. Cinco dias após o início da paralisia, teve crises de vertigem labirintica objetiva e diminuição da audição à direita. o exame otológico mostrou, na parte alta da membrana tímpanica e na pele contígua do fundo do meato acústico externo (correspondendo a área vascular), congestão discreta, com pequenas áreas levemente salientes. O exame foi realizado sob magnificação com o microscópio cirúrgico. Exame otoneurológico - Disacusia de percepcão à direita por lesão periférica (via aérea direita: 250 hertz=60 dBs, $500=70,1.000=60,2.000=70,3.000=100,4.000=100,6.000=90,8.000=90$ ). Via aérea esquerda normal. Ouvido direito testado com mascaramento de $100 \mathrm{dBs}$ (ruído branco). Via óssea díreita: 500 hertz $=50 \mathrm{dBs}, 1.000=50,2.000=55,3.000$ não há audiç̃o, 4.000 não há audição. Via óssea esquerda normal. Via óssea direita testada com mascaramento de 65 dBs. Weber audiométrico lateralizado para a esquerda. Tone decay de 1.000 e 2.000 dentro dos valores normais. Sisi teste em 1.000 e $2.000=60 \%$ e $70 \%$ : discriminação de $30 \%$. Nistagmo espontâneo horizonto-rotatório violento batendo para o lado esquerdo. Desvio espontâneo dos dois index para a direita (em harmonia). Não havia vertigem e nistagmo de posicão. Prova calórica (Hallpike) com eletronistagmografia: hipoexcitabilidade vestibular direita. Ageusia nos 2/3 anteriores da lingua à direita. Lacrimejando sem alteração significativa. Nos territórios dos $5^{\circ}, 9^{\circ}, 10^{\circ}$ e $12^{\circ}$ nervos crânicos nada havia. Radiografias do ouvido Discreto velamento das células da mastóide à direita, na área do ângulo de Citelli (posição de Schüller). Cortes politomográficos da orelha média, labirinto e meato acústico interno mostraram estruturas normais. O otologista enviou relatório ao neurologista com diagnóstico de paralisia facial periférica e comprometimento coclear e vestibular ocasionados provavelmente por vírus. Foi sugerido à paciente que voltasse a consulta com o otologista em 1 a 2 semanas, para novo exame, não só para se saber o que se passava com a paralisia facial, mas também para observar a evolução dos sinais otoscópico e vestibular periférico, isto é, o nistagmo e o desvio do index. A paciente fora medicada com corticóides, complexo B e estriquinina associados a tratamento fisioterápico mediante corrente galvânica.

Como estivesse grávida, a paciente resolveu não retornar à consulta no prazo estipulado, somente o fazendo 4 meses depois. Nesta ocasião, os sinais vestibulares espontâneos tínham desaparecido, mas a paralisia facial, a disacusia e a hipoexcitabilidade vestibular permaneciam inalteradas. Um novo acontecimento veio porém sobrepor-se ao quadro. O exame otoscópico, sob magnificação com microscópico mostrava, agora, pequena perfuração postero-superior da pars tensa, recoberta por massa esbranquiçada fibrinóide aderente à membrana timpânica. Com o micro-gancho e aspirador foi feita limpeza da membrana timpânica, mostrando líquido seroso cristalino na caixa do tímpano que foi aspirado. Foi receitada eritromicina por via oral e cloranfenicol para tratamento tópico. Duas vezes por semana era feita aspiracão da secreção serosa e instllada a solução de cloranfenicol. Este tratamento não extinguiu a secreção e a perfuração ampliou-se espontâneamente. A eletromiografia mostrou desnervação do nervo facial. A causa teria sido um traumatismo? Indagamos à doente e ao marido e a informação foi negativa. Propusemos então intervir cirurgicamente em busca do esclarecimento diagnóstico.

Intervencão cirúrgica - Aberta a mastóide o otologista encontrou a apófise bem pneumatizada, mas as traves ósseas intercelulares estavam destruídas em alguns pontos. A mucosa apresentava-se espessada, fungosa, polipóide e, em certas áreas, com aspecto lardáceo. Havia ainda a presença do mesmo líquido cristalino. A mucosa da caixa do tímpano era pálida, mas nada mais havia de particular. Terminada a mastoidectomia e exposta a apófise horizontal da bigorna, o canal de Falópio 
foi aberto amplamente, desde o primeiro joelho até o buraco estilo-mastóideo (descompressāo do nervo facial). A exposição da porção horizontal do nervo facial foi realizada mediante timpanotomia posterior. A bainha do nervo facial foi aberta: não havia edema mas o nervo apresentava coloração vinhosa. Fragmentos da mucosa foram encaminhados para exame histopatológico e o diagnóstico do patologista foi de processo especifico tuberculoso.

Evolução - O exame tisiológico, feito em seguida, foi inteiramente normal e a reação de Mantoux se mostrou hiperérgica com título de 1:1000. Tratava-se, assim, de mastoidite tuberculosa primitiva. A paciente foi tratada com rifamicina, hidrazida do ácido nicotínico e ethambutol por via sistêmica e rifamicina em uso tópico. Em três meses houve desaparecimento total da secreção do ouvido e a paralisia facial periférica regrediu quase que totalmente.

\section{COMENTARIOS}

Por não apresentar a doente tuberculose pulmonar, tuberculose em outras vísceras ou em outras localizações, é cabivel afastarmos a possibilidade de uma tuberculose ótica? Se é verdade que em doentes com tuberculose em atividade, em particular tuberculose pulmonar avançada, a freqüência de tuberculose ótica é importante (5 a $15 \%$, segundo Calderin ${ }^{4}$ ), a ausência de tuberculose em qualquer outra parte do organismo não pode afastar o diagnóstico como demonstra o nosso caso. Em 500 casos de supurações crônicas de ouvido operados o único caso de otite tuberculosa que encontramos foi o aqui relatado. Ainda mais, nenhum caso de otite média aguda que examinamos foi de origem tuberculosa. Podemos assegurar que, em um total de 1.000 casos de otites médias agudas ou crônicas, o único caso de etiologia tuberculosa foi o presente, e tratava-se, ainda mais, de mastoidite tuberculosa latente. Como comentário final devemos dizer que, segundo informações de familiares, houve regressão de paralisia facial, o que a literatura não costuma registrar.

\section{RESUMO}

Os autores apresentam um caso de paralisia facial periférica devido a uma otite média tuberculosa. Chamam atenção para a raridade atual da otite tuberculosa e para a freqüência com que esta afecção compromete o nervo facial. A regressão da paralisia após tratamento cirúrgico (mastoidectomia e descompressão do nervo facial) e medicamentoso específico foi assinalada.

\section{SUMMARY}

Peripheric facial paralysis and tuberculous otitis media: a case report

In reporting on a case of peripherical facial paralysis due to tuberculous otitis media attention is called both to the present rarity of tuberculous otitis and to the frequency of the attack of this infection to the facial nerve, emphasis being made on the paralysis regression following surgical treatment (mastoidectomy and facial nerve decompression) and use of specific medication. 


\section{REFERENCIAS}

1. AUBRY, M. - Etiologie de paralyes faciales périphériques. Ann. Chir. Plastique 12:6, 1967.

2. BARENGHI, L. \& MILANEZI, I. - L'otite media tubercolare. Arch. Ital Otol. Rin. Laring. 72:262, 1961.

3. CADAR, A. - Otite média tuberculosa na infancia. Sete casos de primc infecçăo. Rev. Assoc. Med. Minas Gerais 19:64, 1967.

4. Calderin, A. M. - Tuberculosis del Oido. Ed. Plus üitra, Madrid, 1946.

5. COURY, C. H.; CONSTANS, P. \& SAIGOT, P. H. - Les tuberculoses de l'otrelle et laryngée associées a tuberculose pulmonaire. Tuberculose et pneumologie 3:192, 1970.

6. FIELDES, J. A. - Tuberculous mastolditis. Laryngoscope 77:489, 1967.

7. KNOTH, J. \& FRITSCHE, F. - Die Otitischen Fazialisparesen im Beobachtungszeitraum von 1954 bis Marz 1967. Das deutsch Gesundheistswesen 23: 1804, 1968.

8. KOHLMOOS, H. W. \& METHENY, J. A. - Tuberculosis of the milddle ear. Laryngoscope $76: 1181,1966$.

9. LANG, R.; LETTI, H. \& SAFFER, M. - Otite tuberculosa primária. Rev. Bras. Otorrinolaring. 36:131, 1970.

10. MARLOWE, F. I. - Primary tuberculous otomastoiditis. Ann. Otol. Rhin. Laring. 81:288, 1972.

11. MIDHOLM, A. \& BRAHE-PEDERSEN, C. - Primary tuberculous otitis media. J. Laryng. Otol. 85:1195, 1971.

12. MIEHLKE, A. - Paralisis del facial. In BERENDES, J.; LINK, R. \& ZOLLHER, F. - Hals, Nasen, Ohren, Hellkunde. Trad. espanhola. Ed. Clentifica Medica, Barcelona, 1969.

13. PIAGET, F. - La tuberculose de l'oreille. Encycl. Med. Chir. (O.R.L.) 20235; 1, 1962.

14. SALTZMAN, S. J. \& RALPH, D. F. - Tuberculous otitis media and mastoiditis. J. Pediat. 79:1004, 1971.

15. SERNADA, D. F. \& BARRETO, L. P. - Sobre um caso de otite média tuberculosa. Rev. brasil. Otorrinol. 32:32, 1964.

16. SMOLER, J.; PINTO, S. L.; VIVAR, G. \& RAMIREZ, J. L. - Tuberculous otitis media, Laryngoscope. 79:488, 1969.

17. STEINBERG, H.; MOLz, w. \& IPPOLITO, C. - Facial paralisys and mastoiditis. Arch. Otolaryng. 76:222, 1962.

18. STONE, J. W. - Tuberculosis of midle ear. Arch. Otolaryng. 86:407, 1967.

19. THEISSING, G. - Tuberculosis del Oldo. In BERENDE, J.; LINK, L. \& ZOLLNER, F. - Hals-Nasen-Ohren-Heilk. Trad. espanhola, Ed. Clentifica Medica, Barcelona, 1969.

20. VAILlAUD, J. C. \& SARROUY, C. H. - Les aspects actuels de la tuberculose congenitale. Revue de la literature a propos d'un cas a début otitique. Le Poumon et le Coeur 24:209, 1968.

21. WILlaMS, J. L. O. - Tuberculosis of the mastoide. J. Laryng. Otol. 79: 355, 1965.

22. WOLFOWITZ, B. L. - Tuberculous mastoiditis. Arch. Otolaryng. 95:109, 1972.

Departamento de Neurologia e Neurocirurgia - Escola Paulista de Medicina - Caixa Postal 5496 - 01000 Sāo Paulo, SP - Brasil. 